\title{
Awareness among MBBS Students About Rise of Violence Against Doctors
}

\author{
Divya Reddy Pannala', S.M. Krishna Sagar ${ }^{2}$, Hemantha Rao Amara ${ }^{3}$, Harshini Deshapathi ${ }^{4}$ \\ ${ }^{1}$ Assistant Professor, Department of Forensic Medicine RVM Institute of Medical Sciences, Siddipet, ${ }^{2}$ Assistant \\ Professor, Department of Forensic Medicine, Mahavir Institute of Medical Sciences, Vikarabad, ${ }^{3}$ Professor, \\ Department of Forensic Medicine, ${ }^{\text {4nd }}$ Year UG, RVM Institute of Medical Sciences, Siddipet
}

\begin{abstract}
World Health Organisation defined workplace violence as incidents where employees are abused, threatened, assaulted or subjected to other offensive behaviour in circumstances related to their work. According to an ongoing study by the Indian Medical Association, over $75 \%$ of doctors have faced violence at work, majority of the cases were reported from emergency wards and Intensive Care Units. In the last decade, Governments of 19 states in India have passed laws for the protection of physicians. However, the law is not being effectively implemented either due to lack of awareness or resistance from administration. A questionnaire based study was conducted on MBBS students to assess their level of awareness about violence on doctors and protection laws. The knowledge among the students about these laws was very low, which could be improved if the topic "Violence on Doctors" is included in the new competency based curriculum, separately in Forensic Medicine subject.
\end{abstract}

Keywords: Awareness, violence, MBBS students, protective laws, competency based curriculum, doctors.

\section{Introduction}

According to World Health Organisation, healthcare workers are four times more likely to be injured due to workplace violence than all other workers combined. ${ }^{1}$ This problem is mainly due to lack of social awareness, poor infrastructure in many hospitals and increasing expectations even during poor prognostic conditions leading to rise in acts of violence against doctors. Hence, it has become necessary to raise awareness regarding this issue and implement stringent regulatory measures to prevent such kind of violent acts.

In a study conducted by Indian Medical Association, over $75 \%$ of doctors across the country have faced at

\section{Corresponding Author:}

\section{Dr. S.M. Krishna Sagar}

Assistant Professor, Department of Forensic Medicine, Mahavir Institute of Medical Sciences

e-mail: krisrocks.37@gmail.com

Mobile Number: 9966780329 least some form of violence and in that, $68.33 \%$ of the violence was committed by the patient attenders or escorts. ${ }^{2}$ But these numbers are underestimated, as most cases of violence are not reported especially in India. In the last decade, Governments of 19 states in India have passed laws for the safeguard of physicians. ${ }^{3}$ However, the law is not being effectively implemented either due to lack of awareness or resistance from administration.

To avoid any serious problems due to violence, a doctor must be well trained in dealing with such incidents. The knowledge on national and state protective laws against violence on doctors is important and they must be included as a part of the teaching curriculum at undergraduate level which would help the upcoming doctors to know about their legal rights. Thus, the current study aims to evaluate the level of awareness about rise in violence against doctors and protection laws amongst the MBBS undergraduates.

\section{Methodology}

This was a cross sectional study done over a period of 2 months from $1^{\text {st }}$ May to $30^{\text {th }}$ June 2020 . 
Questionnaire (dichotomous and multiple-choice questionnaire) was distributed through online survey (google forms) to students of all medical colleges in the states of Telangana and Andhra Pradesh. Based on the completion of the forms within the given study period,
405 MBBS undergraduate students belonging to three academic years $\left(2^{\text {nd }}, 3^{\text {rd }}\right.$ and $4^{\text {th }}$ year MBBS $)$ were a part of this study. The data were analysed in SPPS and expressed as number and percentages and presented in the form of text, tables, and figures.

\section{Results}

Table 1: Awareness on violence

\begin{tabular}{|c|c|c|c|}
\hline \multicolumn{2}{|l|}{ Variables } & \multirow{2}{*}{$\frac{\text { Frequency }}{404}$} & \multirow{2}{*}{$\begin{array}{c}\mathbf{\%} \\
99.8\end{array}$} \\
\hline 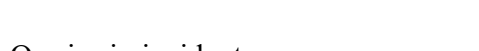 & Yes & & \\
\hline Un Irse in incidents & No & 1 & 0.2 \\
\hline \multirow{4}{*}{ Components of Violence } & All components & 315 & 77.8 \\
\hline & Combination of more than 2 components & 70 & 17.3 \\
\hline & Single Component & 13 & 3.2 \\
\hline & None & 2 & 0.5 \\
\hline \multirow{4}{*}{ Mode of awareness } & Media & 371 & 91.6 \\
\hline & Family & 2 & 0.5 \\
\hline & Friends/Colleagues & 27 & 6.7 \\
\hline & Teachers/Professors in College & 5 & 1.2 \\
\hline \multirow{4}{*}{$\begin{array}{l}\text { Most recent incident you have heard } \\
\text { of/seen/experienced by yourself }\end{array}$} & Assaults in Telangana state & 377 & 93 \\
\hline & Assaults in AP state & 8 & 2 \\
\hline & Assaults in other states & 10 & 2.5 \\
\hline & Could not recall & 10 & 2.5 \\
\hline
\end{tabular}

315 (77.8\%) students mentioned that physical assault, psychological violence including verbal abuse, telephonic threats and warning gestures, damage to medical equipment and damage to clinical establishment constitute as violence on doctors. $12(3 \%)$ students considered violence as only physical assault, $1(0.2 \%)$ as only verbal abuse, $5(1.2 \%)$ of them it a combination of physical and verbal abuse. $70(17.3 \%)$ considered it to be a varying combination of the components. $2(0.5 \%)$ participants did not consider any of the components as violence on doctors.

Table 2: Awareness on laws and punishments protecting doctors

\begin{tabular}{|c|c|c|c|}
\hline \multicolumn{2}{|l|}{ Variables } & \multirow{2}{*}{$\begin{array}{c}\text { Frequency } \\
166\end{array}$} & \multirow{2}{*}{$\begin{array}{l}\% \\
41\end{array}$} \\
\hline 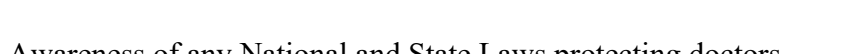 & Yes & & \\
\hline 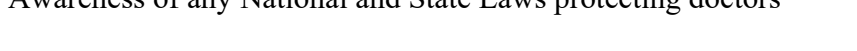 & No & 239 & 59 \\
\hline \multirow{2}{*}{ Special judicial Punishments } & Yes & 188 & 46.4 \\
\hline & No & 217 & 53.6 \\
\hline \multirow{3}{*}{$\begin{array}{l}\text { If punishments for Hurt or Grievous Hurt (as per IPC) would be } \\
\text { applicable for miscreants }\end{array}$} & Yes & 201 & 49.6 \\
\hline & No & 16 & 4 \\
\hline & Don' Know & 188 & 46.4 \\
\hline \multirow{2}{*}{$\begin{array}{l}\text { If punishments are different for assault on doctors from assault on } \\
\text { other health care providers (nurses/paramedical staff)? }\end{array}$} & Yes & 125 & 30.9 \\
\hline & No & 280 & 69.1 \\
\hline
\end{tabular}


$356(87.9 \%)$ of the participants said that the existing laws are not sufficient for protecting doctors whereas 7 $(1.7 \%)$ of them think they are and $42(10.4 \%)$ do not know the answer to the question posed. 345 (85.2\%) of the students mentioned that punishments should vary based on the type and severity of violence and 60 (14.8\%) do not consider so.

Table 3: Method to increase awareness

\begin{tabular}{|c|c|c|c|}
\hline \multicolumn{2}{|l|}{ Variables } & Frequency & $\%$ \\
\hline \multirow{2}{*}{ Conducting workshops and CME programs } & Yes & 366 & 90.4 \\
\hline & No & 39 & 9.6 \\
\hline \multirow{2}{*}{ Participation of student unions for public awareness } & Yes & 401 & 99 \\
\hline & No & 04 & 1 \\
\hline \multirow{2}{*}{$\begin{array}{l}\text { Topic inclusion in Forensic Medicine under new } \\
\text { Competency Based Curriculum }\end{array}$} & Yes & 393 & 97 \\
\hline & No & 12 & 3 \\
\hline
\end{tabular}

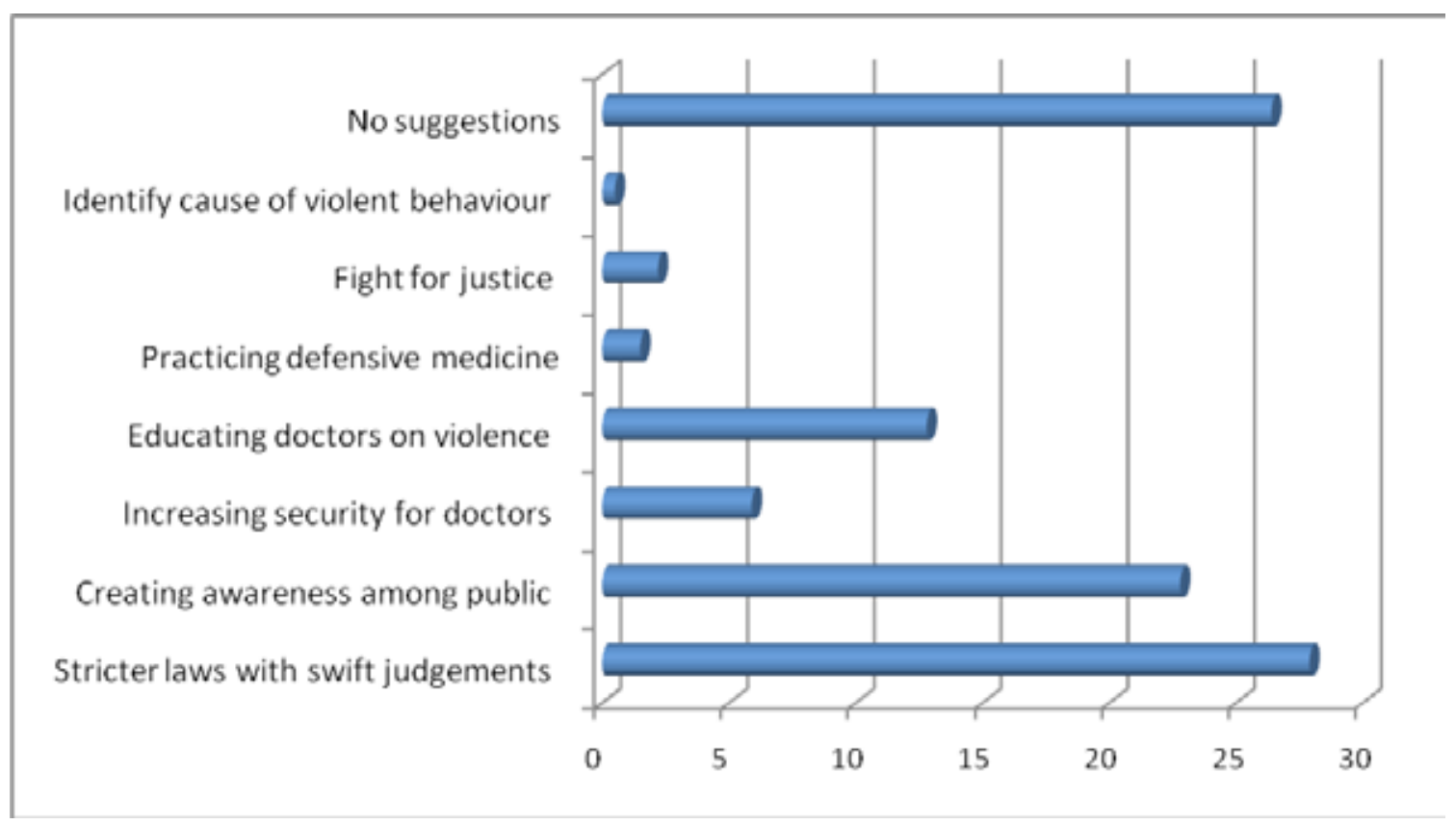

Fig 1: Student suggestions regarding violence on doctors in percentages

\section{Discussion}

Based on a study conducted by Rajesh et al in 2017, there has been a recent rise in vandalism cases, majority of them were reported between 2014 and $2016 .{ }^{4}$ These violent incidents are not exclusive to government hospitals but occurred in private setups too. $99.8 \%$ students were aware of the rise in incidence of violence on doctors. $91.6 \%$ students had heard about these incidences through media, $6.7 \%$ through friends and colleagues and $0.5 \%$ through family. Though media is playing a key role in creating awareness about such incidences, it is known to twist facts for the purpose of sensationalization. Only $1.2 \%$ of the participants were made aware through teachers or professors in college about this issue. Teachers in medical colleges should play a major role by conducting live discussions and debates among students so as to identify, prevent and rectify factors leading to this epidemic rise in violence.

Violence on doctors includes physical assault, verbal abuse, warning gestures, telephonic threats and damage to medical equipment/establishment. ${ }^{5} 77.8 \%$ of the students know what constitutes as violence of the 
remaining 90 students, $13.3 \%$ considered violence as only physical assault and 5.5\% opted for combination of physical assault and verbal abuse. $54.8 \%$ of students, who chose multiple options, did not consider telephonic threats as part of violence. Also, $14.4 \%$ did not consider damage to medical property and $22.2 \%$ did not know that warning gestures constitute violence. When asked to mention about a recent incident they have seen, heard of or experienced, $92.1 \%$ of the participants mentioned about the physical assault that occurred on a medical resident at Gandhi Hospital, Telangana on $9^{\text {th }}$ June 2020. 5.4\% of the participants mentioned various other incidents where doctors were attacked in places like Indore, Kolkata, Vijayawada, etc. All of them had mentioned only about cases where doctors were physical assaulted but none wrote about any incidents involving verbal abuse, damage to clinical establishment or other forms of violence.

Protection of Medicare Service Persons (MPA) and Medicare Service Institutions Acts were passed in 19 states in India. This act was passed in Telangana and Andhra Pradesh in 2008. Even so, 59\% of the participants were unaware of them and as per the Act, offenders can be imprisoned for up to three years and pay a fine of upto Rs.50,000 or double the cost of damage to Medical equipment/establishment. ${ }^{6}$ But, $53.6 \%$ of the students were not aware of the punishments. Offenders can be tried under both the Indian Penal Code (S. 319 and 320 IPC) or MPA Act if they have physically assaulted a doctor. $49.6 \%$ of the students knew that a case can be filed under sections for causing hurt or grievous hurt as per IPC but, $46.4 \%$ were unaware about this. Nurses and Paramedical staff are directly involved in patient care and equally vulnerable to violence. Medicare Protection Act is applicable for doctors as well as other healthcare providers. ${ }^{6}$ But, $30.9 \%$ of the participants are not aware of it.

$87.9 \%$ of the participants did not think that the existing laws are sufficient for protection of doctors from violence. As per study conducted by Gohil RK et al in 2018 , only $20 \%$ of the cases were reported to the police and majority $56.3 \%$ of offenders faced no consequences whereas $23.9 \%$ were issued a verbal warning. ${ }^{7}$ Hence, there is a need for the laws to not only be strengthened but also enforced. Majority of the participants, $85.2 \%$ think that every act of violence on doctors should be thoroughly investigated and punished appropriately, including psychological violence. As per study by Kumar M et al, younger doctors with less work experience were more prone to physical violence. ${ }^{8}$ Hence, it would benefit them if workshops and CME programs were conducted on this issue on a regular basis and $90.4 \%$ of the participants agreed to this.

Study by Kumar M et al concludes that there should be a written policy in the emergency services about the punishments which should be pasted over the walls and other visible areas in hospital vicinity to educate the people. ${ }^{8} 99 \%$ of the students also believe that raising the awareness among public is important which can be done by student unions through social media and other platforms.. Study by Gohil RK et al stated that majority of the doctors are not trained in the measures that need to be taken when facing workplace violence or procedures followed to approach legal help. ${ }^{7}$ Thus, $97 \%$ of the participants want this topic to be included in the new Competency Based Curriculum in Forensic Medicine subject as a separate chapter.

An open ended question was added at the end of the study which required students to write-in their suggestions and comments about the issue which were broadly classified. $27.9 \%$ of the participants mentioned that the government should strengthen the laws relating to violence on doctors and that swift judgements should be passed against the offenders. $22.8 \%$ of them said by raising awareness among the people on this issue, the problem can be curbed. $12.8 \%$ stated that awareness among medical fraternity about precautionary measures and various protective lawsis important. Other suggestions included increasing security in hospitals and emergency wards, identification and elimination of the underlying causes of violent behaviour, practicing defensive medicine and prioritizing saving themselves over their patients and resorting to strikes demanding justice.

\section{Conclusion}

Violence against doctors in India is a multifactorial problem, which may result from unrealistic expectations from doctors, yellow journalism, poor infrastructure in government hospitals or involvement of local leaders/ politicians. In few cases, violent conflicts are inevitable even when proper protocol has been followed by the practitioner or hospital. The existing laws that protect doctors against violence in India are minimal and less stringent, thus resulting in proactive acts of violence due to lenience arising from the current legal scenario. In the current study, it is evident that the level of awareness 
among MBBS students about various protective laws against violence is very low, which should be improved. This can be achieved, if the issue "Violence on Doctors" is included in the new competency based curriculum, separately in Forensic Medicine subject. By incorporating this topic into the new curriculum, it will provide a chance to increase the awareness regarding such acts of violence from the undergraduate level itself, equipping them to handle such incidents in a proper manner legally in their future medical practice.

Ethical clearance: Taken

\section{Conflict of Interest: Nil}

Source of Funding: Nil

\section{References}

1. Dey S. Over $75 \%$ of doctors have faced violence at work, study finds. Times India. 2015;4. Available at: https://timesofindia.indiatimes.com/india/Over75-of-doctors-have-faced-violence-at-work-studyfinds/articleshow/47143806.cms.

2. Martino V.Relationship between work stress and workplace violence in the health sector, Workplace violence in the health sector, Geneva. 2003;1-11. Available at: http://worktrauma.org/health/wv stresspaper.pdf.
3. Saxena S. The forgotten pandemic - violence against doctors. Times of India Blogs. Published on 12.06.2020. Available at: timesofindia.indiatimes. $\mathrm{com} / \mathrm{blogs} / \mathrm{un}$-travesty/the-forgotten-pandemicviolence-against-doctors/

4. RanjanR,Meenakshi, SinghM, Pal R, et al.Epidemiology of violence against medical practitioners in a developing country (2006-2017). J Health Res Rev. 2018; 5(3):153-160.

5. Ghosh K. Violence against doctors: A wake-up call. IJMR. 2018; 148 (2):130-3.

6. The Telangana Medicare Service Persons and Medicare Service Institutions (Prevention of Violence And Damage To Property) Act, 2008. Act No. 11. Available at: indiacode.nic.in/ bitstream/123456789/8676/1/act_11_of_2008.pdf.

7. Gohil RK,Singh P, Saxena N, Patel G.Work place violence against resident doctors of a tertiary care hospital in Delhi, India.ISJ 2019; 6(3):975-981.

8. Kumar M, Verma M, Das T,Pardeshi G. A Study of Workplace Violence Experienced by Doctors and Associated Risk Factors in a Tertiary Care Hospital of South Delhi, India. J Clin Diagn Res. 2016; 10(11): LC06-LC10. 